\title{
Impact of Pre-Monsoonal Rainfall Trend on Vegetation for Ranchi Plateau, Jharkhand, India
}

\author{
Amit Kumar Jha, Ajai Singh and Pratibha Warwade \\ Department of Water Engineering and Management \\ Central University of Jharkhand, Ranchi-835 205, India \\ E-mail: ajai.singh@cuj.ac.in
}

\begin{abstract}
Ranchi has been chosen as the study area to study its changing rainfall pattern, its trend and correlation with vegetation cover during the pre-monsoonal season in the last 20 years. In the year 1998, the western side of the district received a good amount of rainfall but the scenario after that was observed quite alarming. In the next 20 years, the western region received very low rainfall except in the years 2005 and 2014. During 2005, Ranchi received good rainfall in the south-western region of the district. The Eastern region has a good amount of green cover received plenty of rainfall consistently in the last two decades. The central part is the most urbanized zone of the study area having the least green cover. This zone has never received good rainfall in the last two decades. On the contrary despite having good vegetation over the north-western side; the region never received good rainfall. The Non-Parametric trend analysis for the last 20 years shows an overall increase in rainfall with $0.141625 \mathrm{~mm} /$ year and the analysis for the last 117 years showed a significant positive trend in the pre-monsoonal month of February, March, and April while May showed a negative trend. The maximum decrease in rainfall was for February (-0.1804803 mm year $\left.^{-1}\right)$ and the minimum $\left(-0.0007663818 \mathrm{~mm}_{\text {year }}{ }^{-1}\right)$ during April. The overall trend of rainfall during the pre-monsoonal season (March-May) was found increasing $\left(0.02156622 \mathrm{~mm}_{\text {year }}{ }^{-1}\right)$. The rainfall variability pattern showed the maximum value of CV $(105.7 \%)$, whereas premonsoonal rainfall exhibited the minimum value of CV (60.52\%). In general, a high variation of CV was observed which showed that the entire region is very vulnerable to droughts and floods. Disturbance in uniformity of distribution in rainfall pattern and extreme event cases over the district during the pre-monsoonal season in the last two decades was observed.
\end{abstract}

Keywords: Trend analysis, Temporal series, Non-parametric, CV, Pre-monsoon 